\title{
Notification of Terminal Status and Advance Care Planning in Patients with Cancer
}

\author{
Si Won Lee, M.D.* ${ }^{\dagger}$ \\ *Palliative Care Center and ${ }^{\dagger}$ Division of Medical Oncology, Yonsei Cancer Center, \\ Yonsei University Health System, Seoul, Korea
}

As population aging increases the burden of cancer, the quality of death of patients with cancer is emerging as an important issue alongside their quality of life. To improve the quality of death, it is necessary to prepare for death, allowing patients to die comfortably and with dignity at the end. Considering these issues, I aim to discuss the practical aspects of notifying the patient of the terminal phase of cancer and planning for end-of-life care (i.e., advance care planning). When cancer treatment that can extend the patent's lifespan becomes difficult, the patient enters a treatment transition period. Treatment is shifted from life-prolonging care to life-enhancing care, and end-of-life care must be well planned. Medical providers often worry too much about whether the patient will be disappointed or psychologically traumatized when notified of the terminal phase of their cancer, thus delaying plans for end-of-life care. In fact, patients can accept their condition and prepare for end-of-life care better than we expect. During the treatment transition period, notification of terminal status should be given, and a well-prepared advance care plan should be established early when the patient has decision-making ability. In addition to conveying information, it is always necessary to be sensitive to whether the patient and caregiver understand the information and respond to their emotions.

Key Words: Advance care planning, Decision making, Terminal care, Palliative care, Death
Received January 28, 2022

Revised February 11, 2022

Accepted February 14, 2022

\section{Correspondence to}

Si Won Lee

ORCID:

https://orcid.org/0000-0002-2144-4298

E-mail: leesiwon925@yuhs.ac

\section{INTRODUCTION}

Cancer is one of the major causes of death worldwide. In 2020 alone, 19,300,000 people worldwide were newly diagnosed with cancer, and 10 million people died of cancer [1]. In South Korea, 243,837 people were newly diagnosed with cancer in 2018, and 79,153 people died of cancer in 2018 [2]. As the burden of cancer increases due to an aging society, interest in the quality of life of patients with cancer, as well as the quality of death, has become an important issue. Early discussions on end-of-life care are known to improve the quality of life of patients as well as significantly lower meaningless and aggressive treatments such as chemotherapy in the last week before death, admission to an intensive care unit, mechanical respiration, and cardio-pulmonary resuscitation [3,4]. How ${ }^{-}$ ever, there are many cases in which patients with terminal cancer are referred to a palliative care center too late, or $\mathrm{pa}^{-}$ tients or their caregivers refuse to receive palliative care due to misunderstandings about hospice palliative care [5]. Moreover, if patients are not aware of their terminal stage or do not even understand their diagnosis, medical personnel who provide palliative care have difficulty interviewing these patients.

In a survey of 700 oncologists at the Breaking Bad News Symposium hosted by the American Cancer Society in 1998, 
$45.2 \%$ of respondents reported that the most difficult news to tell was that aggressive cancer treatment was not possible anymore and that treatment would be switched to palliative care [6]. The most difficult aspect of telling bad news was being able to tell the news honestly without simultaneously destroying the patient's hope (58\% of respondents). Likewise, it is not easy to notify a patient that he or she is in the terminal stage and then move forward to establish future care plans. Therefore, we suggest and summarize the basic counseling attitudes and methods for terminal notification and advance care planning with patients with cancer.

\section{MAIN TEXT}

SPIKES, as suggested by Baile et al. [6], is a basic 6-stage model that represents methods used to tell bad news. The fundamental principle is gradual communication. A consultation should be initiated in a comfortable environment (Setting) where a patient's privacy is respected and the conversation is undisturbed. Time is spent assessing how much the patient is aware of their disease and its severity (Perception), identifying the patient's desired level of knowledge about their disease (Invitation), and then giving the patient information based on their desired level of knowledge and according to their insight and understanding (Knowledge). At this time, the patient's psychological status is also assessed (Emotion) and support is provided. When the patient is emotionally able to understand and participate, the future treatment plan is established (Strategy and Summary). It is inappropriate for medical personnel to provide a constant stream of information while patients are experiencing significant emotions. While allowing silence and providing appropriate empathy, medical personnel should ask patients about their current thoughts so that they can express their feelings.

When delivering serious news, the goal should be to help the patient understand his or her condition and begin to accept and adapt to the new reality, rather than push them to confront the situation [1]. It is most important that medical personnel are able to recognize and respond to the patient's emotions as they evolve. It is a waste of time to give constant information while patients or caregivers are overwhelmed by emotions and cannot concentrate [1].
The NURSE acronym, as a tool for demonstrating empathy, can be a useful guide for medical personnel on how to respond to patients' or caregivers' emotions (Appendix 1) [7]. The following concepts may not all be necessary in each instance and may not be necessary in a certain order: $(\mathrm{N})$ name the emotion that a patient is feeling (e.g., "You must be very frustrated and disappointed.), (U) understand the emotion (e.g., "This will be a very hard situation.”), (R) respect or praise the patient (e.g., "I am impressed that you endure so well, though it must be difficult."), (S) support the patient (e.g., "My team and I will help you together."), and (E) explore the emotion (e.g., "Please describe in more detail how the situation affects you.").

Notification of terminal status is a turning point in treatment and discussing it is difficult for both medical personnel and patients. In general, patients face a treatment transition period when treatment to delay the cancer progression is no longer possible. Patients may give up their hope of living longer and medical personnel may feel failure because the treatment will not further delay the progression of the disease. However, without terminal status notification, it is difficult for patients to realistically perceive how close death is and to properly plan for the type of treatment they want to receive at the end of their lives. In a study of 332 patients with advanced cancer on the effect on the patient's mental health, after discussion of end-of-life care and terminal status notification, Wright et al. [4] reported that discussing end-of-life care did not cause increased mental disorders, worries, or depression. Instead, patients accepted that their diseases were terminal and preferred treatment that focused on alleviating pain and symptoms instead of meaningless life-prolonging treatment. Hagerty et al. [8] reported that most patients wanted oncologists to notify them first about their conditions and prognosis, not others. Therefore, I hope we can begin the discussion with the belief that patients in a transition period toward end-of-life care are much more accepting than we think.

In the transition toward end-of-life care, the goal of treatment changes from extending the lifespan to providing comfort care and controlling symptoms. This change in treatment goals can cause disappointment, loss, and sadness for patients and caregivers as they face the limitation of contemporary medicine. At this point in the discussion with the patient, it is necessary to draw a big picture and set realistically achievable 
goals [1]. In particular, a patient should never be told, "There is nothing more we can do for you." Although chemotherapy may no longer be an option, palliative treatment can be continued. Such discussions cannot be successful without a sufficient understanding of the patient and the patient's values. The patient in a treatment transition period will be more receptive to resetting future treatment goals if the discussion starts with what the patient values and considers most important. It is necessary to know what is most important to the patient and what expectations and hopes the patient is giving up [1]. We cannot change the reality that patients are experiencing, but providing professional medical knowledge, understanding patients' situations, and supporting patients will finally enable them to have a clear understanding of the changes that they need to accept [1].

When discussing the serious topic of end-of-life planning with patients, it is necessary to look at the overall picture and plan together with the patient and their family [1]. Prior to the discussion, trust must be established between patients and medical personnel [9]. It is not easy for medical personnel to start this discussion if they do not have a rapport with the patient. The medical provider must start by identifying the patient's clinical conditions and explaining them so that the patient and caregivers thoroughly understand the medical condition. After assessing that the patient is ready to proceed to the next level, questions can be asked that help identify the patient's values and goals [1]: "What is the most important thing to you right now?", "Is there anything you want?", "What is happening in your life outside the hospital?" If there are difficulties in decision-making, questions about the concerns that hinder a decision can be asked: "What are you most concerned about right now?", "What is the most difficult part for you right now, and what will be most difficult for your family?" Notification of terminal status and telling bad news should be gradual, and if the patient has difficulty accepting information, the consultation should be stopped and the next consultation planned [9]. If continuing the conversation is possible, recommendations and suggestions can be provided and a new direction suggested in accordance with the patient's goals and feedback. In each process, medical personnel must not forget to carefully assess the feelings of the patient and caregivers, empathize, and respond to them.
Advance care planning is an essential part of planning endof-life care after terminal status notification. Advance care planning, including decisions regarding the withholding or withdrawal of life-sustaining treatment, should be made by medical personnel and patients through shared decision-making. The physician in charge is the ideal primary consultant. However, if this is not possible, the physician in charge at least informs the patient of the necessity of advance care planning and requests consultation support from the multidisciplinary team. A member of the multidisciplinary team, consisting of physicians, nurses, and social workers, will assist the patient with decision-making and completion of the advance care plans [9].

When planning consultation for life-sustaining treatment decisions and care, the patient's decision-making ability must be evaluated first [9]. Decision-making ability refers to the patient understanding of his/her clinical condition and treatment process and ability to make thoughtful treatment decisions. Adults aged 19 years and older are generally considered to have decision-making ability unless their decision-making ability has been professionally assessed and found to be impaired. Impairment of a patient's decision-making ability should not be judged solely on a decrease in cognitive function, and repeated evaluations should be made. If the patient is judged competent to make decisions, treatment discussions should be held with the patient. However, in the clinical setting, even though the patient is competent, the reality is still that making decisions about end-of-life care and the dying process are also centered around families and medical personnel. It is difficult to ignore customs and cultural practices, such as when family members request that the patient not be told the truth or when permission from the family is necessary before informing the patient about a disease with poor prognosis [9]. Difficult situations can arise, such as when interpretations of the patient's decision-making ability vary or when patients who have decision-making ability give up on making decisions [9]. Occasionally, patients completely reject all treatments including medically beneficial treatments, or on the contrary, request treatments that are not medically beneficial. A consensus should be found by fully empathizing and communicating with both patients and families. However, if the consensus gap is wide, help from the ethics committee of the medical institution 
can be requested.

The Counseling Care Manual for Life-Sustaining Treatment Decisions for Medical Personnel is a helpful reference [9]. When life-sustaining treatment planning is discussed for the first time, gradual and repetitive information should be provided as much as possible. Medical personnel assess whether the patient can accept the information and identify the patient's values and goals. Rather than focusing on the futility of treatment, life-sustaining treatment is explained in a way that protects the patient's right to optimal end-of-life care and self-determination. Sufficient time should be provided for the patient and family to process the new information and treatment changes. Most importantly, medical personnel should fully empathize with the feelings of the patient and family throughout the consultation. If a patient refuses to make a decision, medical personnel should provide subsequent consultations to address unresolved issues by understanding the patient's mental state and reminding themselves that the purpose of the system is to protect the patient's rights. Rapport with the patient can be built by showing support and encouraging the patient's decisions. Furthermore, a life-sustaining treatment plan is a way to protect the patient's optimal end-of-life care and right to self-determination; rather than giving up on treatment, care and treatment will continue. If the discussion is made with the patient's family due to the patient's inability to make decisions, it is necessary to fully understand the family members' feelings and provide comfort. They may experience vague feelings of guilt about the process of making decisions for the patient. The criteria for decision-making by the family should be to make a decision that the patient would make for himself/herself, with health personnel encouraging them to take this into consideration [9]. Examples of consultation for terminal notification and life-sustaining treatment planning from the Counseling Care Manual for Life-sustaining Treatment Decisions for Medical Personnel are presented in Appendix 2 and Appendix 3 [9].

\section{CONCLUSION}

Cancer patients' quality of life and death improves when end-of-life care planning, including life-sustaining treatment, is appropriately well planned during the treatment transition period. Therefore, to prepare for high-quality end-oflife care, discussions should not be delayed. Sufficient time for consideration is necessary for patients and caregivers when they have decisions to make, and delayed discussions may create unnecessary burdens for medical personnel. Patients must prepare early to ensure quality of death, with optimal end-oflife care and protection of their dignity and value as human beings.

\section{CONFLICT OF INTEREST}

No potential conflict of interest relevant to this article was reported.

\section{ORCID}

Si Won Lee, https://orcid.org/0000-0002-2144-4298

\section{SUPPLEMENTARY MATERIALS}

Supplementary materials can be found via https://doi. org/10.14475/jhpc.2022.25.1.42.

\section{REFERENCES}

1. Back A, Arnold RM, Tulsky J. Mastering communication with seriously ill patients : balancing honesty with empathy and hope. New York:Cambridge Univeristy Press;2009.

2. Hong S, Won YJ, Lee JJ, Jung KW, Kong HJ, Im JS, et al. Cancer statistics in Korea: incidence, mortality, survival, and prevalence in 2018. Cancer Res Treat 2021;53:301-15.

3. Bernacki RE, Block SD, American College of Physicians High Value Care Task Force. Communication about serious illness care goals: a review and synthesis of best practices. JAMA Intern Med 2014;174:1994-2003.

4. Wright AA, Zhang B, Ray A, Mack JW, Trice E, Balboni T, et al. Associations between end-of-life discussions, patient mental health, medical care near death, and caregiver bereavement adjustment. JAMA 2008;300:1665-73. 
5. Hawley P. Barriers to access to palliative care. Palliat Care 2017;10:1178224216688887.

6. Baile WF, Buckman R, Lenzi R, Glober G, Beale EA, Kudelka AP. SPIKES-A six-step protocol for delivering bad news: application to the patient with cancer. Oncologist 2000;5:302-11.

7. Fischer GS, Tulsky JA, Arnold RM. Communicating a poor prognosis. Topics in Palliative Care 2000;5:75-94.

8. Hagerty RG, Butow PN, Ellis PM, Lobb EA, Pendlebury SC, Leighl N, et al. Communicating with realism and hope: incurable cancer patients' views on the disclosure of prognosis. J Clin Oncol 2005;23:1278-88.

9. Kim M. Counseling care manual for life-sustaining treatment decisions for medical personnel. Seoul:Korea National Institute for Bioethics Policy;2020. 
Appendix 1. The N.U.R.S.E. Acronym, a Valuable Tool for Demonstrating Empathy.

\begin{tabular}{ccl}
\hline & Concept of demonstrating empathy & \multicolumn{1}{c}{ Example* $^{*}$} \\
N & Name the emotion & "You must be very frustrated and disappointed." \\
R & Understand the emotion & "This will be a very hard situation." \\
$S$ & Respect (praise) the patient & "I was impressed that you endure so well, though it must be difficult." \\
E & Support the patient & "My team and I will help you together." \\
\hline
\end{tabular}

*Source: Fischer GS, Tulsky JA, Arnold RM. Communicating a poor prognosis. Topics in Palliative Care 2000;5:75-94. 
Appendix 2. Examples of Terminal Notification Consultations.

\begin{tabular}{|c|c|}
\hline $\begin{array}{l}\text { Consultation methods for } \\
\text { terminal notification }\end{array}$ & Examples* \\
\hline Building trust & $\begin{array}{l}\text { - I have seen many patients over X years. Based on my experience, you are currently in this condition. } \\
\text { - How do you feel these days? Do things feel very hard? }\end{array}$ \\
\hline Beginning diagnosis of terminal stage & $\begin{array}{l}\text { - What do you think of your current condition? Have you ever worried about your current condition? } \\
\text { - I have to tell you some difficult news. It looks like your disease has progressed. } \\
\text { - In a medical emergency, medical personnel must perform life-sustaining treatments such as restoring heart function } \\
\text { with CPR or connecting a respirator by intubation to prolong a patient's life. It would be best to think about } \\
\text { whether you wish to receive such life-sustaining treatment in order to be prepared for this situation. } \\
\text { - The disease is now in ___ stage, so critical situations can occur at any time. To be prepared for these situations, } \\
\text { I think it would be best to decide in advance which life-sustaining treatments you want. }\end{array}$ \\
\hline Explaining diagnosis to a patient & 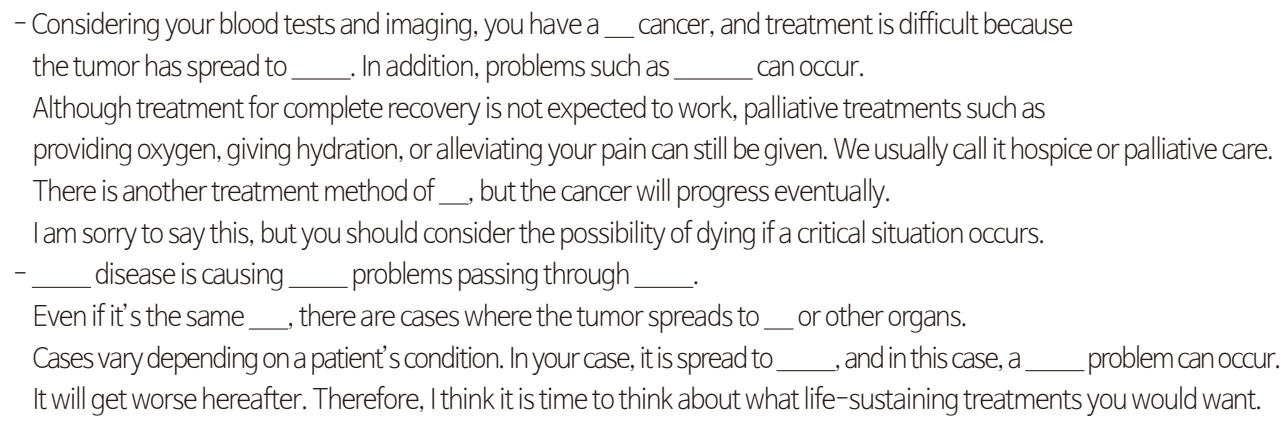 \\
\hline $\begin{array}{l}\text { Explaining prognosis to } \\
\text { a patient without insight }\end{array}$ & $\begin{array}{l}\text { - A case when a patient is unaware of the disease though he/she has been diagnosed with stomach cancer: } \\
\text { You have gastritis right now and I see other problems as well. } \\
\text { - A case of an elderly patient: Because of your age, getting better is not likely and the likelihood of getting worse is high. }\end{array}$ \\
\hline
\end{tabular}

*Source: Kim M. Counseling care manual for life-sustaining treatment decisions for medical personnel. Seoul:Korea National Institute for Bioethics Policy;2020. 
Appendix 3. Consultation Examples of Life-Sustaining Treatment Planning.

\begin{tabular}{|c|c|}
\hline $\begin{array}{l}\text { Consultation methods for } \\
\text { life-sustaining treatment planning }\end{array}$ & Examples* \\
\hline $\begin{array}{l}\text { Explaining the life-sustaining } \\
\text { treatment decision system }\end{array}$ & 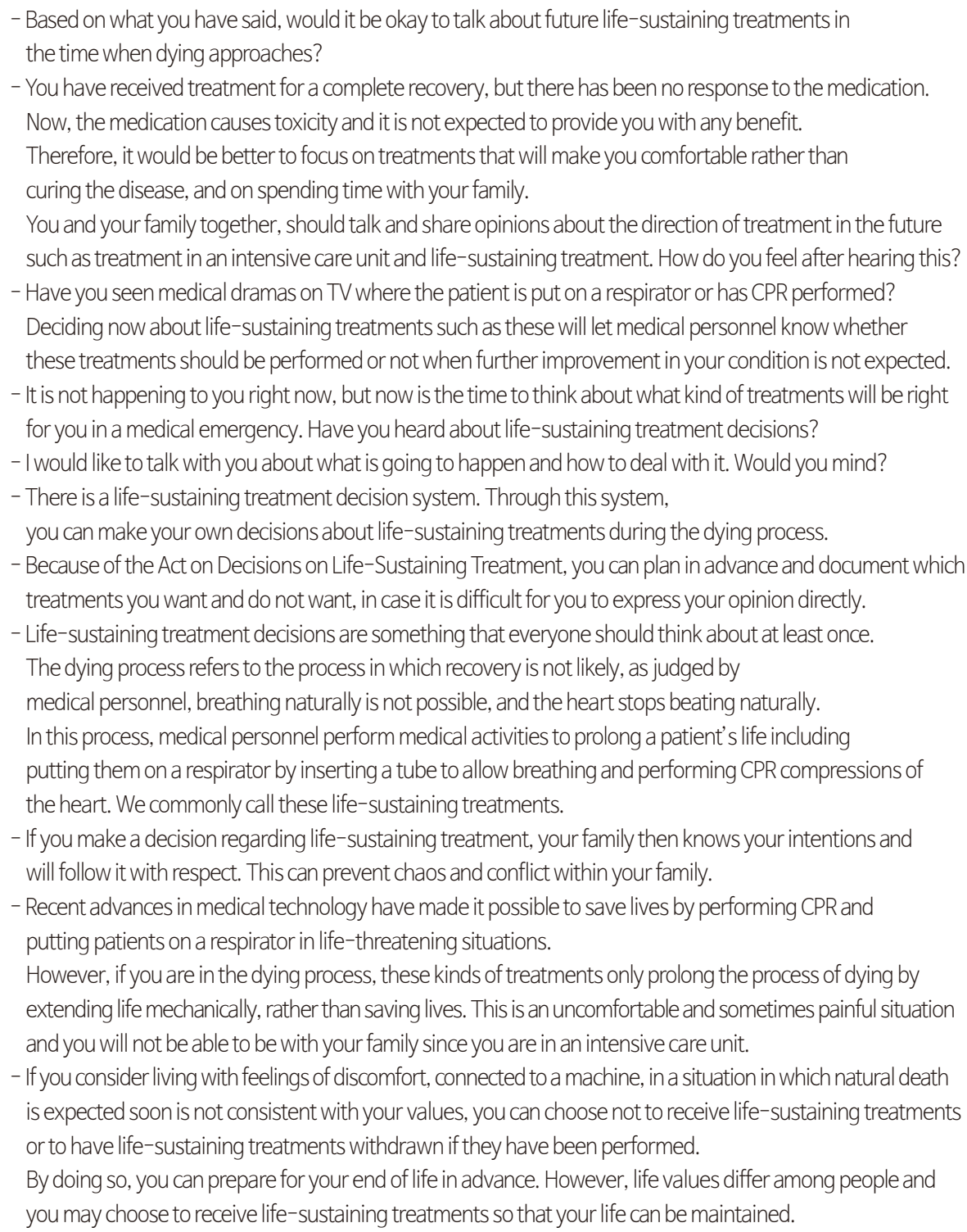 \\
\hline Identifying patients' values and treatment goals & $\begin{array}{l}\text { - Considering your current medical condition, what is most important to you? } \\
\text { - If there are not many days left to live, what are your wishes? } \\
\text { - If you think about the future, what worries you the most? }\end{array}$ \\
\hline
\end{tabular}

*Source: Kim M. Counseling care manual for life-sustaining treatment decisions for medical personnel. Seoul:Korea National Institute for Bioethics Policy;2020. 